University of Nebraska - Lincoln

DigitalCommons@University of Nebraska - Lincoln

Daugherty Water for Food Global Institute:

Faculty Publications

Daugherty Water for Food Global Institute

2006

\title{
OPTIMAL MANAGEMENT OF GROUNDWATER OVER SPACE AND TIME
}

Nicholas Brozovic

David L. Sunding

David Zilberman

Follow this and additional works at: https://digitalcommons.unl.edu/wffdocs

Part of the Environmental Health and Protection Commons, Environmental Monitoring Commons, Hydraulic Engineering Commons, Hydrology Commons, Natural Resource Economics Commons, Natural Resources and Conservation Commons, Natural Resources Management and Policy Commons, Sustainability Commons, and the Water Resource Management Commons

This Article is brought to you for free and open access by the Daugherty Water for Food Global Institute at DigitalCommons@University of Nebraska - Lincoln. It has been accepted for inclusion in Daugherty Water for Food Global Institute: Faculty Publications by an authorized administrator of DigitalCommons@University of Nebraska Lincoln. 
Published as Brozović N., Sunding D., Zilberman D. (2006) Optimal Management of Groundwater over Space and Time. In: Goetz RU., Berga D. (eds) Frontiers in Water Resource Economics. Natural Resource Management and Policy, vol 29. Springer, Boston, MA, pp 109-135.

\title{
OPTIMAL MANAGEMENT OF GROUNDWATER OVER SPACE AND TIME
}

\author{
Nicholas Brozović \\ Department of Agricultural and Consumer Economics \\ University of Illinois at Urbana-Champaign \\ nbroz@uiuc.edu \\ David L. Sunding \\ Department of Agricultural and Resource Economics \\ University of California, Berkeley \\ David Zilberman \\ Department of Agricultural and Resource Economics \\ University of California, Berkeley
}

\section{INTRODUCTION}

For nearly half a century, groundwater has been portrayed in the economic literature as a typical common property resource. Numerous studies of groundwater extraction have analyzed the externalities imposed by users on each other. ${ }^{1}$ A large body of work offers clear prescriptions in the form of optimal policy instruments, and a similarly large body of work advocates the needlessness of any centralized intervention. Yet existing theoretical models of groundwater extraction implicitly make two strong assumptions about the underlying behavior of the resource. First, the spatial distribution of resource users is assumed to be irrelevant. Second, path-independence of the resource is assumed: the history of past extraction does not affect present and future extraction decisions. 
Relaxing either of these assumptions may undermine the results of existing work.

The purpose of this chapter is to present a model for the extraction of a pathdependent resource by spatially distributed users. The example of groundwater is used to demonstrate the incorporation of the physics of a complex natural system into an economic model of dynamic resource use. In particular, the optimality conditions can be calibrated to parameters found in actual aquifers to model the range of behavior encountered in the real world. This demonstrates the failure of existing models of groundwater extraction to describe aquifers adequately.

The analysis presented in this chapter emphasizes the tradeoffs between the spatial extent of each user's private property right, the physical parameters of the system, and the spatial and temporal distribution of extraction. Several important principles emerge from the model. Some aquifers, even if they constitute a single hydrological entity: (1) are more akin to private property than common property (see the end of section 3.2), and (2) have significant lagged effects from pumping (see Proposition 2). In such cases, use of traditional dynamic common property models will result in misleading or incorrect analyses and policy prescriptions. The model presented is quite general and can also be applied to other resources where externalities are diffusional in nature, such as oilfields or patchy marine fisheries.

This chapter is organized into several sections. We begin with a simple description of the physics of groundwater flow and contrast this to the representation of flow in existing economic models of groundwater. Following this, a theory for the optimal extraction of groundwater by multiple spatially distributed users from a hydrologically realistic, path-dependent aquifer is presented. Although the model we present is intended to allow incorporation of groundwater flow equations taken from the engineering and hydrology literature, it is also general enough to nest many existing economic models of groundwater use (see Appendix C). Discussion of the optimality conditions from this model emphasizes how the results differ from existing studies and the implications for groundwater management policy.

\section{A SIMPLE DESCRIPTION OF THE HYDRAULICS OF GROUNDWATER FLOW}

Ongoing pumping from a well in an aquifer induces horizontal hydraulic gradients towards the well. Because of these gradients, a localized 'cone of depression' develops around the well. The dimensions of a cone of depression will depend not only on the pumping rate through time, but also on the hydrogeological variables that describe the physical properties of the aquifer (see the first appendix). However, for an aquifer with homogeneous physical 
properties, a well pumping large quantities of water will have a deeper, wider cone of depression than a well pumping small quantities.

Moreover, if the cones of depression of adjacent wells overlap, well interference will occur and the water level in both wells will decrease correspondingly. Because of the physics of water flow, even though well interference is spatially variable, it is also linearly additive. Hence, the total drawdown of the aquifer at any point caused by pumping from any number of wells is the sum of the drawdowns caused by each individual well at that point (Figure 1.1). Aquifers show an important additional behavior in response to withdrawals of water. As described in the first appendix, the water level in a well does not adjust instantaneously to changes in pumping rate. Instead, adjustments to changes in pumping are gradual and cumulative. Thus, the entire history of water extractions determines the state of the groundwater resource at any point in time.

In most real-world aquifers, there are multiple independent and heterogeneous users that each pump groundwater. Each user's pumping will affect the pumping costs of all the other users. Each possible pair of users will thus have an idiosyncratic set of effects on each other. Bilateral impacts will depend on both the distance between the two users and the history of past pumping at each well. Moreover, these impacts will be lagged: a change in one user's behavior may not be observed by other users for some time.

Economic studies of groundwater extraction use one of three different models to represent aquifers: single-cell, two-cell, and multi-cell. None of these models adequately capture either the spatial interdependency among pumpers or the path-dependency property described above. However, in order to understand exactly how the model described in this chapter differs from previous work, each type of model and its implicit assumptions will be discussed.

The simplest aquifer representation is the single-cell aquifer (first described in detail by Brown and Deacon [3]). In a single-cell aquifer, the state of the groundwater resource is entirely described by a single variable, generally the volume of water remaining in the aquifer or the depth to water. This aggregation of the resource stock represents an implicit assumption that the water level is uniform throughout the aquifer. Because of this, single-cell models are often referred to as 'bathtub' or 'milk-carton' models. In such a system, no matter where, or from how many places in the bathtub (or milk-carton) liquid is extracted, the depth of the liquid throughout the container remains uniform. Hence, in an unconfined single-cell aquifer, drawdown of the water table is uniform throughout the aquifer irrespective of both the location of pumping wells relative to each other and their relative contributions to the aggregate extraction (Figure 1.2). Although in principle, path-dependency of the resource could be incorporated into a single-cell models, to date this has not been undertaken. Instead, in discrete-time formulations, changes in the resource depend only on the previous period's extraction $[5,9]$. In continuous time formulations, 

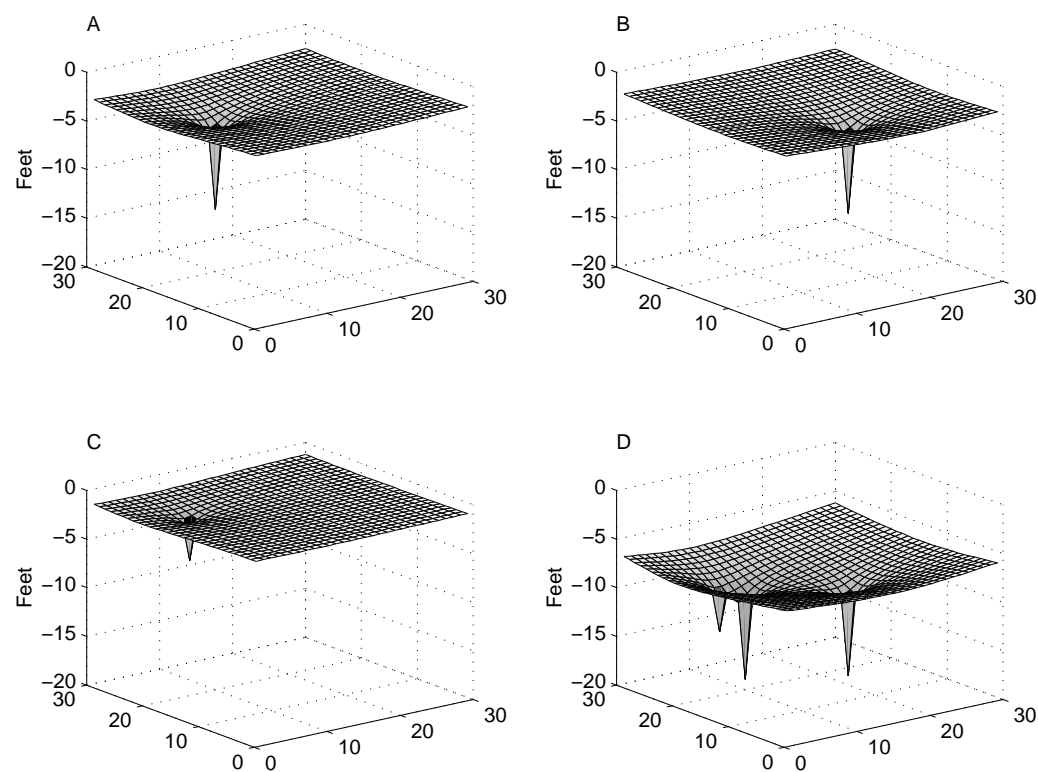

Figure 1.1 Drawdown from multiple wells in an aquifer. Panels A through C represent the drawdown caused by three separate wells in an aquifer whose behavior is governed by the hydraulic response equations (see the first appendix). In each panel, the units of the vertical axis are feet, and of the horizontal axes, miles. Before the start of pumping, the aquifer was assumed to have a uniform depth of zero feet. Panels A and B show the spatial distribution of drawdown after one year resulting from two wells in different locations, each pumping 600,000 gallons a day. Panel C shows the distribution of drawdown after a year for a third well pumping 300,000 gallons a day. Panel D shows the resultant drawdown if all three wells pumped simultaneously for a year. Storativity and transmissivity values are within the range found in normal aquifers (storativity taken as $10^{-3}$, transmissivity as $10^{5} \mathrm{gal} / \mathrm{day} / \mathrm{ft}$ ). Note that (1) cones of depression are localized to the vicinity of each pumping well; (2) drawdown is greater for the wells with larger pumping rates; and (3) well interference is greater between wells that are closer together (see Panel D). 

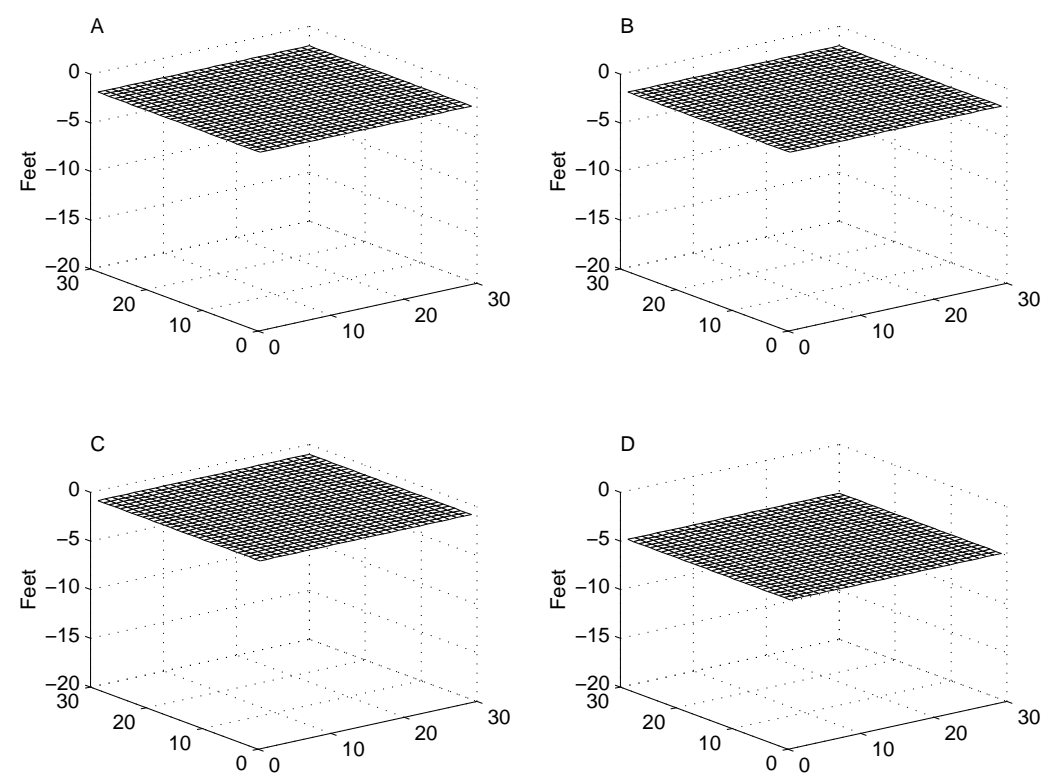

Figure 1.2 Drawdown from multiple wells in a single-cell aquifer. Axes in this figure are identical to those in Figure 1.1. It is assumed that the single cell aquifer has areal dimensions 30 miles by 30 miles. Panels A through C show the drawdown of the water table due to three spatially separated wells pumping for one year. The well locations and pumping rates are the same as in Figure 1.1. Panel D shows the resultant drawdown if all three wells pumped simultaneously for a year. Note that Panels A and B are identical, and that the depth to the water table remains uniform, irrespective of the position of pumping.

the resource stock adjusts instantaneously to the extraction rate (for example, Gisser [11] or Koundouri [16]). The focus of this chapter is the presentation and analysis of a path-dependent groundwater extraction model with spatial heterogeneity. However, for ease of comparison, Appendix B derives the optimality conditions for groundwater extraction from a single-cell aquifer in discrete time. Appendix C shows how this single-cell model nests within our more general framework.

A somewhat more complicated aquifer representation is the two-cell model, where several single-cells are mutually connected by porous boundaries [6, $8,15,27] .{ }^{2}$ Each component cell in a two-cell model behaves exactly like a single-cell. There is also flow between the two cells that is proportional to the difference in stock levels between them. However, in existing models the rate 
of this adjustment only depends on instantaneous stock differences between the component cells, and there is no role for extraction history.

Finally, in multi-cell aquifer models, water movement between cells is determined by finite difference approximations to the equations of groundwater flow $[2,21,22]$. Multi-cell models are usually calibrated to individual groundwater basins and provide specific management guidelines rather than general results. Early contributions to this literature did not involve any optimization, but instead compared the effects of simple rule-of-thumb policies [2]. More recent work has used separate physical models of groundwater behavior and economic models of the benefits of water use. Most of these papers simulate aquifer behavior under various pumping scenarios and then use a linear regression of the physical model as the vector state equation in the economic modeling $[21,22]$. The numerical simulations employed in such models are generally hydrologically accurate. As such, they do capture path-dependency of the groundwater resource. However, in linearizing the physical model for inclusion in the economic model, only the previous period's state and control variables are used. This is a misspecification of the physical model that removes the role of extraction history. Hence, lagged groundwater pumping externalities cannot be analyzed in an economic context using such models.

\section{OPTIMAL EXTRACTION OF A PATH-DEPENDENT RESOURCE BY SPATIALLY DISTRIBUTED USERS \\ 3.1 THE MODEL}

Consider an aquifer whose behavior is governed by the hydraulic response equations (1.A.4) to (1.A.6) described in the first appendix to this chapter. Water is to be extracted from the aquifer by $J$ separate users over an $N$-period horizon. These users are spatially distributed with known, fixed locations relative to each other and to the resource, and each owns a single well. ${ }^{3}$ In any period $t=1, \ldots, N$, the net benefit of each user $j=1, \ldots, J$ from the resource is given by the function $f\left(u_{j t}, x_{j t}\right)$, which captures both the benefits and costs of resource extraction. The decision variable $u_{j t}$ is user $j$ 's per-period water extraction at time $t$. Assume that $f\left(u_{j t}, x_{j t}\right)>0, \partial f\left(u_{j t}, x_{j t}\right) / \partial u_{j t}>0$ and $\partial^{2} f\left(u_{j t}, x_{j t}\right) / \partial u_{j t}^{2}<0$. The state variable $x_{j t}$ is defined as the pumping lift of water at the $j$ th well at time $t$. Assume that $\partial f\left(u_{j t}, x_{j t}\right) / \partial x_{j t}<0$, as per-period benefits decrease as the pumping lift increases. Also assume that $\partial^{2} f\left(u_{j t}, x_{j t}\right) / \partial u_{j t}^{2} \leq 0$, so that pumping costs increase at least linearly with depth. Note that in every period, $x_{j t}$ is determined not only by user $j$ 's previous extraction history, but also by the extraction history of all the other users. Appendix A provides more details on the determination of pumping lifts through time. The variable $s(t, r)$ in that appendix is equivalent to $x_{j t}$ 
in the model presented in this section; here we follow standard optimization notation for state and control variables for ease of interpretation. Similarly, the difference in pumping rates for a well between successive periods, $\left(u_{j t}-u_{j t-1}\right)$, is equivalent to the incremental pumping $\Delta Q$ in Appendix $\mathrm{A}$.

The $N$-period optimization problem for the aquifer is given by

$$
\max \sum_{t=1}^{N} \beta^{t} \sum_{j=1}^{J} f\left(u_{j t}, x_{j t}\right)
$$

where $\beta$ is the per-period discount factor, with $\beta<1$. The aquifer is spatially heterogeneous, so that each well will have a different pumping lift determined by all previous pumping histories. The $J$ equations of motion describing the level of water over time in each of the $J$ wells are

$$
x_{j t+1}=\sum_{i=1}^{J} \sum_{n=1}^{t}\left(u_{i n}-u_{i n-1}\right) w(t-n+1, r(i, j)) ; t=1, \ldots, N-1
$$

where $w(t, r(i, j))$ is the well function defined by equation (1.A.4) and $r(i, j)$ is the distance between wells $i$ and $j$. Note that there are no 'cells' in this analysis. The pumping lifts in the aquifer resulting from drawdown of multiple wells form a continuous surface and are defined for every point in the aquifer. However, only the lifts at pumping wells enter the objective function. Without loss of generality, it is assumed that $x_{j 0}=0$ for all $j$. Note that because the state of the resource at all periods after $N$ is unimportant, there are only $(N-1) J$ equations of motion in total.

Whereas in many problems in the optimal extraction of resources over time, the Hamiltonian and optimal control theory are the most convenient solution concepts, this is not the case here. In the discrete time formulation, the presence of lagged effects leads to equations of motion for the resource that are summations rather than difference equations. Because of this, the method of Lagrange multipliers is more convenient in order to derive the necessary conditions for this problem. ${ }^{4}$ The appropriate Lagrangian expression for the problem described by equations (1.1) and (1.2) is

$$
\begin{aligned}
L= & \sum_{t=1}^{N} \beta^{t} \sum_{j=1}^{J} f\left(u_{j t}, x_{j t}\right)+ \\
& +\sum_{t=1}^{N} \sum_{j=1}^{J} \lambda_{j t}\left\{\left(\sum_{i=1}^{J} \sum_{n=1}^{t}\left(u_{i n}-u_{i n-1}\right) w(t-n+1, r(i, j))\right)-x_{j t+1}\right\}
\end{aligned}
$$

The first order conditions for an interior solution are:

$$
\frac{\partial L}{\partial x_{l s}}=\beta^{s} \frac{\partial f\left(u_{l s}, x_{l s}\right)}{\partial x_{l s}}-\lambda_{l s-1}=0
$$




$$
\begin{aligned}
\frac{\partial L}{\partial u_{l s}}= & \beta^{s} \frac{\partial f\left(u_{l s}, x_{l s}\right)}{\partial u_{l s}}+\sum_{j=1}^{J} \lambda_{j s} w(1, r(l, j))+ \\
& +\sum_{t=s+1}^{N} \sum_{j=1}^{J} \lambda_{j t}(w(t-s+1, r(l, j))-w(t-s, r(l, j)))=0
\end{aligned}
$$

By definition, $w(0, r(l, j))=0$, so that condition (1.5) may be rewritten in more compact form as

$$
\begin{aligned}
\frac{\partial L}{\partial u_{l s}}= & \beta^{s} \frac{\partial f\left(u_{l s}, x_{l s}\right)}{\partial u_{l s}}+ \\
& +\sum_{t=s}^{N} \sum_{j=1}^{J} \lambda_{j t}(w(t-s+1, r(l, j))-w(t-s, r(l, j)))=0
\end{aligned}
$$

The adjoint variable $\lambda_{j t}$ is the marginal present value shadow price of the state variable at well $j$ at time $t$. Defining the transformation $\lambda_{j k}=\beta^{k} \mu_{j k}$ where $\mu_{j k}$ is the marginal current value shadow price of water ${ }^{5}$ at well $j$ at time $k$ allows us to restate conditions (1.4) and (1.6) in current value form:

$$
\begin{gathered}
\frac{\partial f\left(u_{l s}, x_{l s}\right)}{\partial x_{l s}}-\beta^{-1} \mu_{l s-1}=0 \\
\frac{\partial f\left(u_{l s}, x_{l s}\right)}{\partial u_{l s}}+\sum_{t=s}^{N} \sum_{j=1}^{J} \beta^{t-s} \mu_{j t}(w(t-s+1, r(l, j))-w(t-s, r(l, j)))=0
\end{gathered}
$$

The double summation in condition (1.8) may be written in simplified notation as

$$
\frac{\partial f\left(u_{l s}, x_{l s}\right)}{\partial u_{l s}}+\sum_{t=s}^{N} \sum_{j=1}^{J} \beta^{t-s} \mu_{j t} \theta(t-s, r(l, j))=0
$$

The function $\theta(t-s, r(l, j))$, which is the difference between well functions in successive time periods, is the incremental drawdown caused at well $j$ at time $t$ by a unit of pumping at well $l$ at time $s$. Sufficient conditions for optimality are joint concavity of $f\left(u_{l s}, x_{l s}\right)$ in $u_{l s}$ and $x_{l s}$.

\subsection{RESULTS}

Equation (1.7) shows that for an optimal solution, the marginal benefit to each groundwater user of a further unit of pumping lift equals the difference between the capital gain and opportunity costs to that user of the additional pumping lift. Equation (1.9) relates the benefit of pumping an additional unit 
of water to the discounted future costs of that pumping for all users. Hence, condition (1.9) captures the lagged, idiosyncratic effects of resource extraction. Several key insights about the behavior of the optimal solution emerge from these two necessary conditions.

Proposition 1 (Role of spatial interdependency). The further a well is from its nearest neighbor wells, the larger its optimal pumping in each period.

Proof: Because summation is a linear operator, we can demonstrate the result using only two wells without loss of generality. Recall that $f\left(u_{j t}, x_{j t}\right)>0$, $\partial f\left(u_{j t}, x_{j t}\right) / \partial u_{j t}>0$ and $\partial^{2} f\left(u_{j t}, x_{j t}\right) / \partial u_{j t}^{2}<0$. Moreover, the adjoint variable is negative by definition of the state variable. Hence, from equation (1.9), we need to show that

1. $(w(t+1, r)-w(t, r))>0$ and

2. $\partial / \partial r\{w(t+1, r)-w(t, r)\}<0$.

The first result follows immediately from the definition of the well function in equation (1.A.4), as

$$
\begin{aligned}
w(t+1, r)-w(t, r) & =\frac{1}{4 \pi T}\left(\int_{\frac{r^{2} S}{4 T(t+1)}}^{\infty} \frac{e^{-z}}{z} d z-\int_{\frac{r^{2} S}{4 T t}}^{\infty} \frac{e^{-z}}{z} d z\right) \\
& =\frac{1}{4 \pi T}\left(\int_{\frac{r^{2} S}{4 T(t+1)}}^{\frac{r^{2} S}{4 T t}} \frac{e^{-z}}{z} d z\right)>0
\end{aligned}
$$

To show the second result, note that

$$
\begin{aligned}
\frac{\partial}{\partial r}\{w(t+1, r)-w(t, r)\}= & \frac{1}{4 \pi T}\left(\frac{e^{\frac{-r^{2} S}{4 T t}}}{r^{2} S / 4 T t} \cdot \frac{2 r S}{4 T t}-\right. \\
& \left.-\frac{e^{\frac{-r^{2} S}{4 T(t+1)}}}{r^{2} S / 4 T(t+1)} \cdot \frac{2 r S}{4 T(t+1)}\right) \\
= & \frac{1}{2 \pi T r}\left(e^{\frac{-r^{2} S}{4 T t}}-e^{\frac{-r^{2} S}{4 T(t+1)}}\right) \\
< & 0
\end{aligned}
$$

Thus, because the magnitude of the externality imposed by one user on another depends on their distance from one another, where two users are close together, they will each optimally pump less water. $\|$ 
Proposition 2 (Role of extraction history). The maximum effect of a user's pumping need not be felt immediately. As distance from a pumping well increases, the time lag between a change in pumping at that well and the maximum effect of that pumping will also increase.

Proof: Two separate results are needed:

1. The sign of $\partial / \partial t\{w(t+1, r)-w(t, r)\}$ is ambiguous. This implies that the effects of a given change in pumping as felt at any distance $r$ may increase or decrease with time.

2. As $r$ increases, the time $\widehat{t}$ at which $\partial / \partial t\{w(\widehat{t}+1, r)-w(\widehat{t}, r)\}=0$ also increases.

To show the first result, calculate the appropriative derivative:

$$
\begin{aligned}
\frac{\partial}{\partial t}\{w(t+1, r)-w(t, r)\} & =\frac{1}{4 \pi T}\left(\frac{e^{\frac{-r^{2} S}{4 T(t+1)}}}{t+1}-\frac{e^{\frac{-r^{2} S}{4 T t}}}{t}\right) \\
& =\frac{1}{4 \pi T(t+1)}\left(e^{\frac{-r^{2} S}{4 T(t+1)}}-\frac{t+1}{t} e^{\frac{-r^{2} S}{4 T t}}\right) \\
& =\frac{e^{\frac{-r^{2} S}{4 T t}}}{4 \pi T(t+1)}\left(e^{\frac{r^{2} S}{4 T(t+1)}}-\frac{t+1}{t}\right)
\end{aligned}
$$

Now, note that for large $t, e^{\frac{r^{2} S}{4 T t(t+1)}}-\frac{t+1}{t}$ will be negative, whereas for large $r$ and $S$, and small $t$, it will be positive. Thus, the sign of $\partial / \partial t\{w(t+1, r)$ $-w(t, r)\}$ is ambiguous.

To show the second result, define $\widehat{t}$ such that $e^{\frac{r^{2} S}{4 T t(t+1)}}-\frac{\widehat{t}+1}{\widehat{t}}$, so that $\partial / \partial t\{w(\widehat{t}+1, r)-w(\widehat{t}, r)\}=0$. From this it is clear that if $r$ increases, $\widehat{t}$ must also increase. $\|$

Proposition 3. A spatially uniform policy will only be optimal if there are an infinite number of wells uniformly distributed above the aquifer.

Proof: In order for any uniform policy to be optimal, the double summation $\sum_{t=s}^{N} \sum_{j=1}^{J} \beta^{t-s} \mu_{j t} \theta(t-s, r(l, j))$ must be equal for all pairs of well users $j$ and $l$, and for all periods $s$. From Propositions 1 and 2, this can only be true if every well has the same spatial distribution of wells around it.

From Proposition 3, it follows that if there are an infinite number of uniformly distributed wells, the optimal policy will be spatially uniform. However, unlike 
in a single-cell aquifer, this does not mean that the resource is common property. Idiosyncratic externalities are still present, but each well receives the same overall distribution of idiosyncratic effects. Hence, the more spatially nonuniform well distribution is, the more the optimal policy will also be nonuniform across space, even if the individual resource users have identical net benefit functions for water, as is the case in this analysis.

Assuming that the initial condition of the aquifer is not at the optimal steady state, and that $N=\infty$, equations (1.7) and (1.9) allow solution of the optimal trajectory to reach that steady state. Solution of this system of equations is computationally intensive, and requires explicit spatial locations for each groundwater user. However, analysis of the optimal steady state is also informative. Given the assumptions made about the infinite areal extent of the aquifer (see the first appendix), every finite pumping combination will reach a steady state. ${ }^{6}$ The optimal steady state is defined by a set of state variables $x_{1}^{*}, x_{2}^{*}, \ldots, x_{J}^{*}$ and a set of control variables $u_{1}^{*}, u_{2}^{*}, \ldots, u_{J}^{*}$. In a steady state, condition (1.7) implies that

$$
\mu_{l}^{*}=\beta \frac{\partial f\left(u_{l}^{*}, x_{l}^{*}\right)}{\partial x_{l}^{*}}
$$

Substituting into condition (1.9) yields

$$
\frac{\partial f\left(u_{l}^{*}, x_{l}^{*}\right)}{\partial u_{l}^{*}}+\sum_{j=1}^{J} \frac{\partial f\left(u_{j}^{*}, x_{j}^{*}\right)}{\partial x_{j}^{*}} \sum_{t=s}^{\infty} \beta^{t-s+1} \theta(t-s, r(l, j))=0
$$

Now, the infinite series of well functions in the second term of the left hand side is a convergent sequence with finite sum, so that the steady state condition may be simplified to

$$
\frac{\partial f\left(u_{l}^{*}, x_{l}^{*}\right)}{\partial u_{l}^{*}}=-\sum_{j=1}^{J} \frac{\partial f\left(u_{j}^{*}, x_{j}^{*}\right)}{\partial x_{j}^{*}} \sum_{t=1}^{\infty} \beta^{t} \theta(t-1, r(l, j))
$$

Equation (1.15) relates the optimal steady state marginal value of pumping to the discounted cost to all users of that additional unit of pumping in the future. The summation $\sum_{t=1}^{\infty} \beta^{t} \theta(t-1, r(l, j))$ can be thought of as a weighting function that determines the relative importance placed on each user's steady state marginal benefit by user $l$. It captures both the spatial interdependency between pairs of users and the lagged nature of the groundwater externality.

For an aquifer system with two groundwater users, condition (1.15) may be represented in a convenient graphical form. Although such as a system only contains a single bilateral relationship, linearity of the summation operator means that key features of the optimality condition are preserved. Moreover, such a graphical analysis provides an intuitive way to demonstrate the important differences between this model and existing groundwater economics models. 


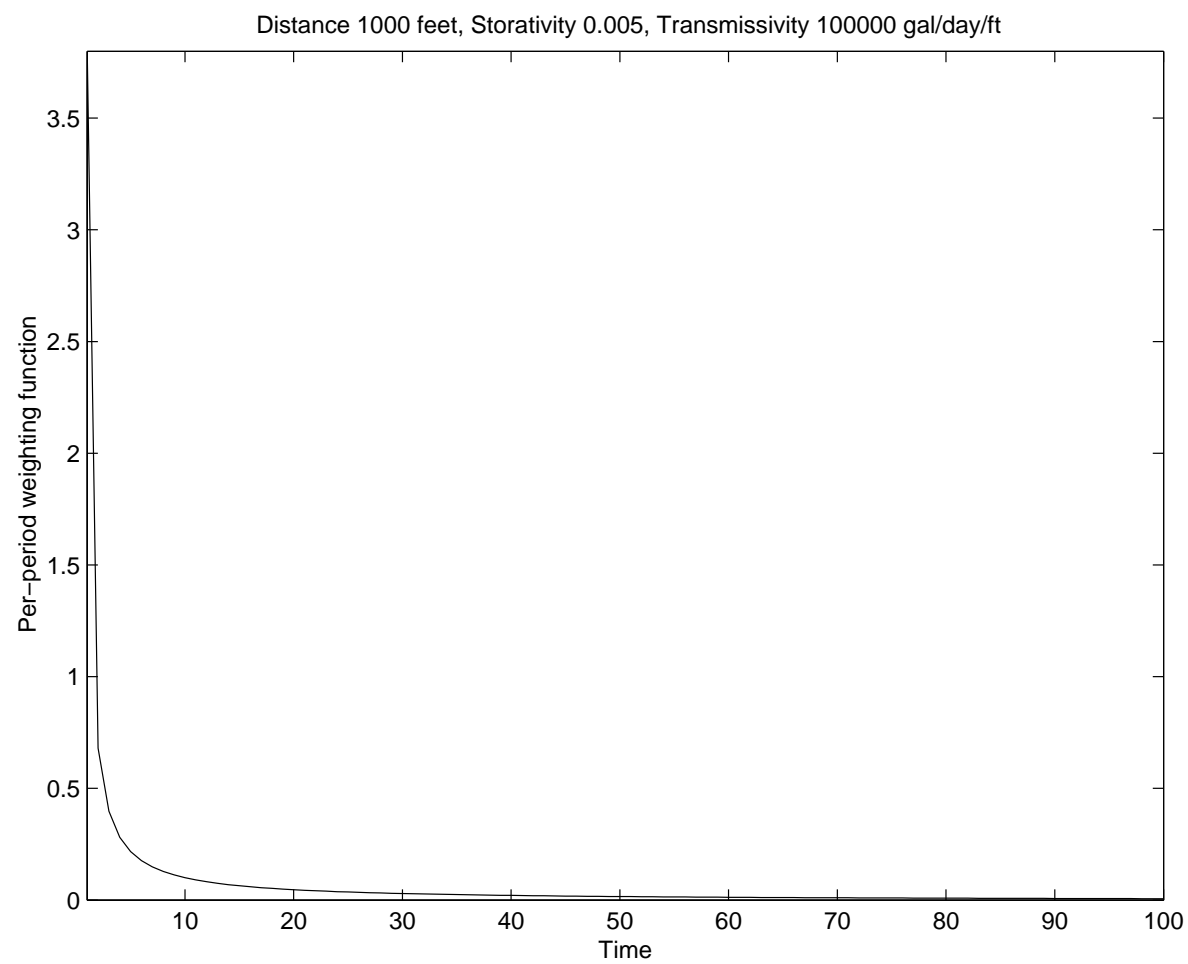

Figure 1.3 Per-period weighting function through time for a steady-state aquifer. This graph presents the impacts through time, per unit time, of a unit change in pumping from a well on a second groundwater user located 1000 feet from the first well. The units of time are in months. Storativity and transmissivity values are within the range found in normal aquifers (storativity taken as $10^{-3}$, transmissivity as $10^{5} \mathrm{gal} / \mathrm{day} / \mathrm{ft}$ ). Note that the per-period weighting function $\beta^{t} \theta(t-1, r(l, j))$ is discounted.

First, consider the discounted components of the weighting function from equation (1.15), which for each period $t$ are given by $\beta^{t} \theta(t-1, r(l, j))$. For a given distance between the two wells $j$ and $l$, and for a given set of hydrological parameters $S$ and $T$, a plot of $\beta^{t} \theta(t-1, r(l, j))$ against time shows the importance of lagged effects in determining when the effects of pumping by one user (namely drawdown of water in the well) are transmitted to the other user (Figures 1.3 and 1.4).

As expected from Proposition 2, if the two pumping wells are a small distance apart, only pumping in the immediate past has any relevance. The majority of the impact resulting from any change in pumping occurs immediately (Figure 1.3). No significant additional drawdown occurs more than several periods after a change in the pumping schedule. 


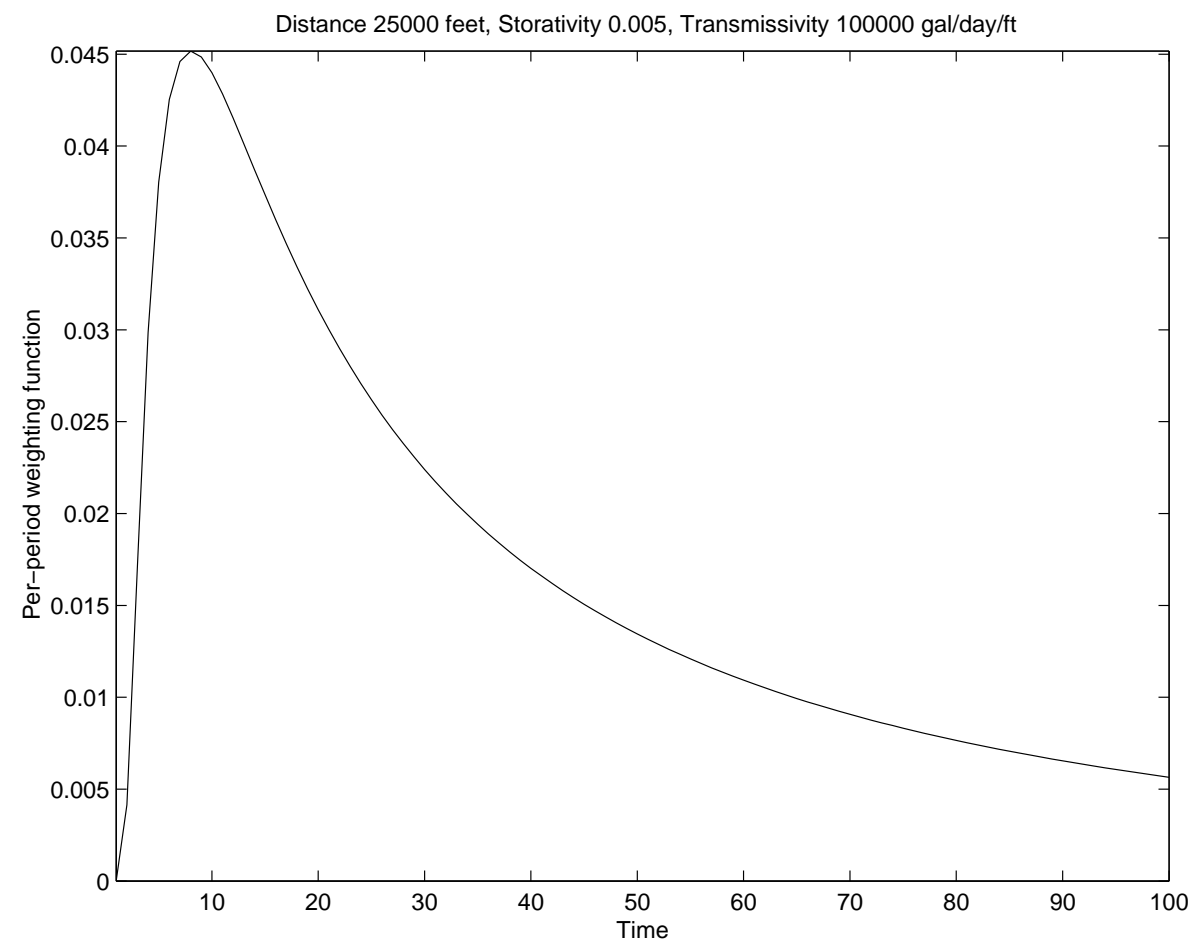

Figure 1.4 Per-period weighting function through time for a steady-state aquifer. This graph presents the impacts through time, per unit time, of a unit change in pumping from a well on a second groundwater user located 50000 feet from the first well. The units of time are in months. Storativity and transmissivity values are within the range found in normal aquifers (storativity taken as $10^{-3}$, transmissivity as $10^{5} \mathrm{gal} / \mathrm{day} / \mathrm{ft}$ ). Note that the per-period weighting function $\beta^{t} \theta(t-1, r(l, j))$ is discounted. 
Recall that from Proposition 2, lagged effects become more and more important as distance between the users increases. Hence, at larger distances from a pumping well, users feel no immediate effects from changes in the other users' pumping. Instead, the effects of changes that occurred several periods ago are much more significant (Figure 1.4). Indeed, even with discounting, users a large distance apart from each other place much more importance on the other's actions many periods ago, and no weight on their present actions. Moreover, the impacts of changes in pumping may persist for many years. Note also the difference in the magnitude of the per-period weighting function between Figures 1.3 and 1.4. At a distance of around 10 miles from a pumping well, the second user is far less concerned with changes in the other user's pumping than at a distance of 1000 feet.

At an optimal steady state, the summation $\sum_{t=1}^{\infty} \beta^{t} \theta(t-1, r(l, j))$ represents the time-integrated total importance to a groundwater user of a unit change in pumping by any other user. If we assume an effective well radius for each user, this weighting function is also defined for the future effects of a user on the water levels in his own well. By normalizing the weighting function by a user's own weighting function, it is possible to consider the relative importance that a user places on other user's groundwater withdrawals as a function of distance (Figures 1.5 and 1.6). By definition, a user will place a relative value of one on withdrawals from his own well. A bilateral relationship with a neighboring well that has a relative value of 0.9 implies that the user cares almost as much about withdrawals from this well as about his own withdrawals. Conversely, a value of 0.1 suggests that the two wells interfere very little with each other.

As might be expected, in aquifers with high storativities and low transmissivities, the relative weighting functions decrease rapidly with distance (Figure 1.5). This implies that in general, groundwater users are unconcerned about other users' extraction rates at any distances away from their wells. As a result of this, we suggest that some aquifers with very high storativities and very low transmissivities should not be modeled as common property. On the other hand, in aquifers with low storativities and high transmissivities, the values of the relative weighting function remain high even at large distances (Figure 1.6). In such aquifers, each groundwater user's extraction does impact all other users. However, note that for all realistic hydrogeological parameter ranges, the greatest impact on the water level in any well is always caused by pumping from that well. By comparison, in single-cell aquifer models, the relative weighting function is one for all groundwater users, irrespective of distance from one another. This is another way of stating the implicit assumption of single-cell models that extraction from any well affects all users equally (to see this graphically, compare Figures 1.1 and 1.2). As Figures 1.5 and 1.6 suggest, this assumption may be quite unrealistic. 


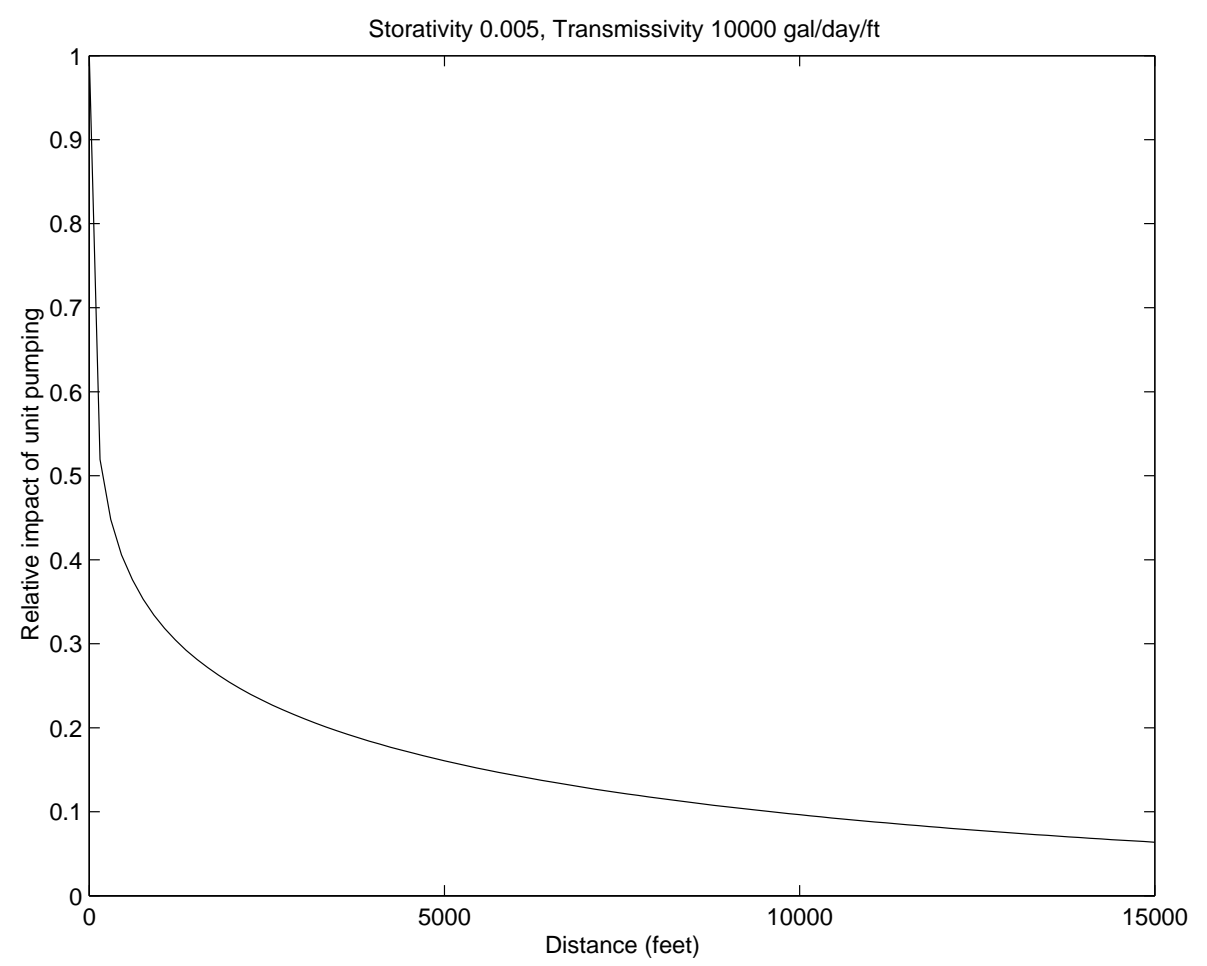

Figure 1.5 Total relative impacts of pumping as a function of distance. The vertical axis is the normalized weighting function, defined for a distance $r$ as $\frac{\sum_{t-1}^{\infty} \beta^{t} \theta(t-1, r)}{\sum_{t-1}^{\infty} \beta^{t} \theta(t-1,1.5)}$. The normalized weighting function is the total weighting function at $r$ divided by the weighting function measured at the effective well radius, taken here as 1.5 feet. Figure 1.5 represents an aquifer with high storativity and low transmissivity. The graph can be interpreted as follows. A unit of water withdrawn by user $j$ one mile away from user $l$ will have less than $20 \%$ of the impact that user $l$ will have on himself through withdrawing one unit of water. Similarly, the transmitted effect for a pumping well at a distance of 3 miles is less than $10 \%$ of the own-effect. 


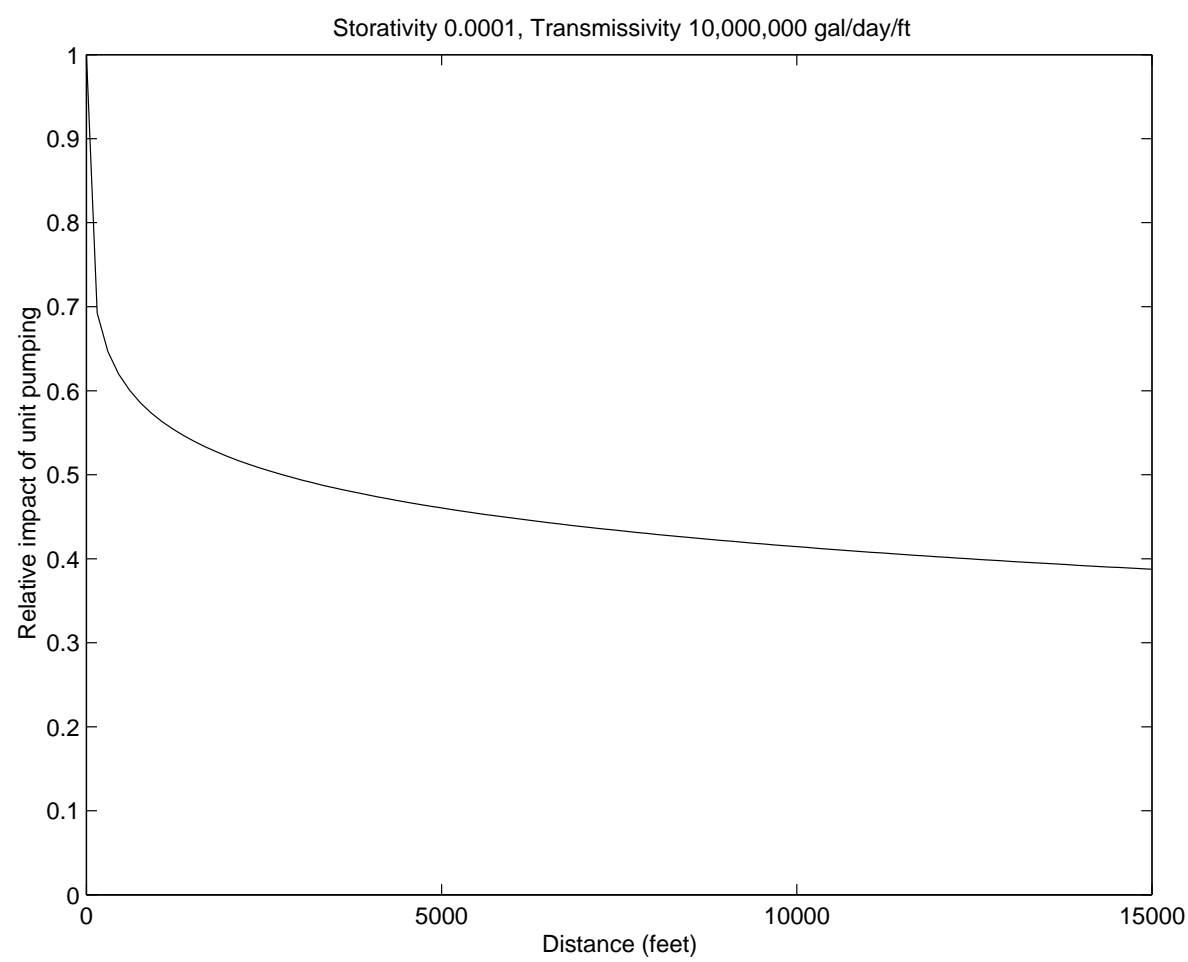

Figure 1.6 Total relative impacts of pumping as a function of distance. The vertical axis is the normalized weighting function, defined for a distance $r$ as $\frac{\sum_{t-1}^{\infty} \beta^{t} \theta(t-1, r)}{\sum_{t-1}^{\infty} \beta^{t} \theta(t-1,1.5)}$. The normalized weighting function is the total weighting function at $r$ divided by the weighting function measured at the effective well radius, taken here as 1.5 feet. Figure 1.6 represents an aquifer with low storativity and high transmissivity. The graph can be interpreted as follows. A unit of water withdrawn by user $j$ one mile away from user $l$ will have around $45 \%$ of the impact that user $l$ will have on himself through withdrawing one unit of water. Similarly, the transmitted effect for a pumping well at a distance of 3 miles is still almost $40 \%$ of the own-effect. 


\section{POLICY IMPLICATIONS}

An influential body of literature has focused on the magnitude of the welfare gain from optimal control of groundwater compared to competitive outcomes $[1,11,12,16]$. This work has emphasized the apparently negligible welfare difference between optimal control rules and competitive outcomes without any government intervention.

Whether advocating optimal management or no intervention, all of these studies have used single-cell aquifers. As explained in this paper, such models fail to capture adequately important aspects of the behavior of real aquifers. Because of this, policy recommendations based on such models, even when they provide both apparently robust and intuitively appealing results, should be viewed with caution.

As the analysis above has demonstrated, many groundwater aquifers should not be modeled as common property. Under certain hydrological conditions (such as shown in Figure 1.6), effects of pumping may be widely transmitted throughout the aquifer. However, in other aquifers, the extent of the externality imposed by one user on other users is limited (Figure 1.5). In such settings, the aquifer is more akin to a private property resource than a common property resource.

Herein lies the failure of the single-cell model to capture adequately aquifer hydraulic response. Single-cell models predict that there are few gains to be made from optimal groundwater management in aquifers with high storativities [11]. With the more realistic aquifer response function, it remains true that there are the least gains from optimal groundwater management in high storativity aquifers. However, such aquifers also least resemble a single-cell as the aquifer response is localized to the immediate vicinity of the pumping wells. In other words, gains from optimal management are minimized because the resource is close to private property to begin with. Conversely, for the situation which most resembles a single-cell aquifer (low storativity and high transmissivity), the gains from optimal groundwater management over no intervention will be larger.

Given the complexity of the underlying resource, it is not surprising that the optimal policy should vary idiosyncratically across space and time. Clearly, it is not feasible to implement such a policy in real groundwater management situations. Which second-best instrument will have the best equity and efficiency effects will depend on the spatial distribution of wells, as well as the individual demand functions for water and local hydrological parameters. It is not possible to rank second-best policies without extensive numerical simulations.

It is a common preconception that in the United States, there is an almost complete lack of groundwater regulations. Whether advocating the introduction of new policies or the needlessness of any intervention, this notion has underlain 
many of the economic studies of groundwater. However, it is not correct to say that groundwater regulations are generally absent. Many states have wellspacing regulations that determine the minimum distance between adjacent wells. Moreover, there is a large variation in these regulations, from wellspacing requirements of 4 miles in portions of the Dakota aquifer in Kansas, to 300 feet or less in many counties in Texas.

Well-spacing regulations cannot be analyzed at all using a single-cell aquifer model. Because of this, even though they represent a pervasive environmental regulation, they have been entirely ignored in the economic literature. Indeed, because this study shows that the greatest impacts from any pumping are always closest to the well head, it is likely that a simple well-spacing regulation will have excellent efficiency and equity effects in some aquifers. It is conceivable that under some conditions, well-spacing regulations are more appropriate than uniform taxes or quotas. The extent to which actual well-spacing regulations reflect underlying hydrological parameters, and how they correspond to an economically defined optimal spacing, are empirical questions left to future work.

Like water, oil is a fugitive resource, and the same equations of flow govern its subsurface behavior. However, in the oil industry, there has been a widespread failure of well-spacing regulations to prevent over-exploitation [17, 26]. One possible explanation of this is that the extraction rate of oil implies well-spacing regulations that are impossible to enforce given the surface area of individual oil leases. Instead, there have been attempts at oil field unitization as a management tool. Interestingly, in some groundwater basins under extreme overdraft, resource policy has also de-emphasized well-spacing requirements and moved towards basin-wide adjudication with quantity restrictions.

\section{CONCLUSIONS}

This chapter has presented a model for the extraction of a spatially heterogeneous, path-dependent resource by multiple spatially distributed users. The occurrence of lagged effects in such a model implies that some users may care far more about the past actions of other users than their present actions, even with discounting. In the presence of idiosyncratic effects between pairs of resource users, the optimal policy entails tradeoffs between the physical parameters of the system, individual demand functions, and the explicit spatial distribution of individual users.

Existing economic models of groundwater extraction have made assumptions about the behavior of the underlying resource that are unrealistic. In particular, the prevalence of single-cell models means that spatial aspects of policy have been entirely ignored. The assumption that groundwater is a typical common property resource drives many of the results in the existing literature. This 
chapter incorporates equations of motion for the state of the resource, based on the physics of water flow, into the spatially distributed groundwater extraction problem. The results shown here demonstrate that in some cases, groundwater is much closer to a private property resource than a common property resource. This is the correct physical explanation for why, at least in some cases, there may be little welfare gain from moving to an optimal extraction policy. Moreover, this analysis suggests that some of the county-level groundwater regulations observed in the real world (and ignored in previous literature) may actually be quite efficient second-best policy solutions.

\section{Appendix: The hydraulics of groundwater flow}

Theoretical analyses of groundwater flow in the civil engineering and hydrology literature are based on the physics of water flow towards a well during pumping (for example, see [7] or [10] for more detailed derivations of the groundwater flow equations).

Consider an extremely simple aquifer. For analytical simplicity, we assume that it has the following five properties:

1. The aquifer is horizontal.

2. The aquifer has infinite areal extent.

3. The aquifer is of constant thickness.

4. Impermeable layers above and below confine the aquifer.

5. The aquifer is homogeneous and isotropic (meaning that hydrogeological parameters are constant within the aquifer and also equal in all directions).

Before proceeding, it is necessary to define two parameters describing the physical properties of the aquifer. The storativity of a confined aquifer is the volume of water released from storage per unit of surface area per unit decrease in the hydraulic head. Storativity is dimensionless and may be thought of as the capacitance of the aquifer. The range of storativities found in confined aquifers is 0.005 to 0.00005 [10]. Aquifer transmissivity is defined as the hydraulic conductivity of the aquifer multiplied by its thickness, where the hydraulic conductivity is a constant of proportionality relating specific discharge from a region to the hydraulic gradient across it. The range of values of observed transmissivities varies across over thirteen orders of magnitude from around $5 \times 10^{-7} \mathrm{gal} / \mathrm{day} / \mathrm{ft}$ for unfractured igneous and metamorphic rocks to around $10^{8} \mathrm{gal} / \mathrm{day} / \mathrm{ft}$ for unconsolidated gravels. Aquifers suitable for well development generally have higher transmissivities.

Theis [25] was the first to derive an analytical solution for transient well response to pumping. In addition to the assumptions about aquifer structure 
described above, the Theis solution also assumes a pumping system where only a single well is pumping at a constant rate from the aquifer. Moreover, it is assumed that the well penetrates the entire depth of the aquifer, has an infinitesimal diameter, and that before the start of pumping, hydraulic head is uniform throughout the aquifer. Given a constant pumping rate $Q$, the drawdown of the aquifer $s$ at any point a distance $r$ from the well, at time $t$ after pumping begins is defined as

$$
s(t, r)=\frac{Q}{4 \pi T} \int_{a}^{\infty} \frac{e^{-z}}{z} d z
$$

where

$$
a=\frac{r^{2} S}{4 T t}
$$

and $S$ is the storativity, and $T$ is the transmissivity. The integral in equation (1.A.1) is the exponential integral of order one, a well-known integral whose value is given by

$$
\int_{x}^{\infty} \frac{e^{-u}}{u} d u=-\alpha-\ln x-\sum_{n=1}^{\infty}(-1)^{n} \frac{x^{n}}{n \cdot n !}
$$

where $\alpha=\lim _{n \rightarrow \infty}\left(1+\frac{1}{2}+\frac{1}{3}+\cdots+\frac{1}{n}-\ln n\right) \approx 0.577216$ is Euler's constant. For notational ease, it is convenient to define the well function $w(t, r)$ where $t$ is the time since pumping started and $r$ is the Euclidean distance from the well, as

$$
w(t, r)=\frac{1}{4 \pi T} \int_{\frac{r^{2} S}{4 T t}}^{\infty} \frac{e^{-z}}{z} d z
$$

which is an exponential integral of order one multiplied by a scaling factor. The well function is a convenient parameterization for hydrologic analysis. Note that in most hydrological literature, the well function is given without the scaling factor $1 / 4 \pi T$. It is included within the well function here solely for simplicity of notation in the main analysis. Then, the drawdown at distance $r$ and time $t$, given constant pumping rate $Q$, is given by $s(t, r)=Q w(t, r)$.

The Theis solution assumes a single pumping well and constant pumping rates. However, it can easily be extended to include both pumping rates that vary through time and multiple wells (for example, see Domenico [7]). Because of linearity of the underlying transient flow equations, arithmetic summation of independent well functions can be used to calculate the drawdown through time at any point in the aquifer with multiple wells whose pumping rates vary. For example, if there are $J$ wells pumping at constant rates $Q_{1}, Q_{2}, \ldots, Q_{J}$ with well $j$ starting to pump at time $t_{j}$, then for a point that is at distances $r_{1}, r_{2}, \ldots, r_{J}$ from the pumping wells, drawdown at time $t$ is given by

$$
s\left(t, r_{1}, r_{2}, \ldots, r_{J}\right)=Q_{1} w\left(t_{1}, r_{1}\right)+Q_{2} w\left(t_{2}, r_{2}\right)+\cdots+Q_{J} w\left(t_{J}, r_{J}\right)
$$


From equations (1.A.1) and (1.A.5), it follows that the drawdown at any point in an aquifer depends on the location and sequence of all past pumping, so that the resource is path-dependent. The principle of superposition may also be used for the case of a single well with variable pumping rates. Assume that the initial pumping rate is $Q_{0}$, and that at times $t_{1}, t_{2}, \ldots, t_{K}$ this rate is incremented by $\Delta Q_{1}, \Delta Q_{2}, \ldots, \Delta Q_{K}$. Then the drawdown at a distance $r$ from the pumping well at time $t$ is given by

$$
s(t, r)=Q_{0} w(t, r)+\Delta Q_{1} w\left(t-t_{1}, r\right)+\cdots+\Delta Q_{K} w\left(t-t_{K}, r\right)
$$

where the well function is zero if $t \leq t_{K}$. For economic analysis of groundwater extraction, equations (1.A.5) and (1.A.6) can be incorporated into the equations of motion for the pumping lifts in each well, given in equation (1.2).

\section{Appendix: Revisiting optimal extraction from a single-cell aquifer}

Consider an aquifer in which there are $J$ pumping agents, each with identical per-period individual benefit functions $f\left(u_{j t}, x_{t}\right)$. The first and second order derivatives of $f\left(u_{j t}, x_{t}\right)$ satisfy equivalent conditions to those in Section 3. As in Section $3, u_{j t}$ is the pumping of individual $j$ during period $t$. However, in a single-cell aquifer, there is only one state variable, denoted here by $x_{t}$. Here, we define $x_{t}$ to be the depth from the surface to groundwater, or equivalently, the pumping lift. Thus, all groundwater users, irrespective of their individual pumping, will have to pump water from the same depth. The $N$-period optimization problem for the aquifer is then given by

$$
\max \sum_{t=1}^{N} \beta^{t} \sum_{j=1}^{J} f\left(u_{j t}, x_{t}\right)
$$

where $\beta$ is the per-period discount factor, with $\beta<1$. The equation of motion of the state variable is given by

$$
x_{t+1}=x_{t}+\sum_{j=1}^{J} \gamma u_{j t}+R ; t=1, \ldots, N-1
$$

In the single-cell aquifer, one parameter fully describes the hydrologic response of the system to pumping. This parameter is $\gamma$, and it is a constant of proportionality linking the effect of a unit withdrawal of water from the aquifer to the resultant increase in the pumping lift. Note also that per-period recharge is fixed. In the absence of pumping, there is no steady state solution to this system, and the aquifer will continue to fill towards an infinite height above the ground. This somewhat unrealistic assumption is standard within the groundwater economics literature (e.g. [3, 12]). 
Equation (1.B.2) may be rewritten as a summation

$$
x_{t+1}=\sum_{k=1}^{t} \sum_{j=1}^{J}\left(\gamma u_{j k}+\widetilde{R}\right) ; t=1, \ldots, N-1
$$

where $\widetilde{R}=R / J$ and, without loss of generality, we can set the initial stock level to zero. Assuming that an interior solution exists, the problem represented by equations (1.B.1) and (1.B.3) can be solved by the method of Lagrange multipliers. The appropriate Lagrangian is

$$
L=\sum_{t=1}^{N} \beta^{t} \sum_{j=1}^{J} f\left(u_{j t}, x_{t}\right)+\sum_{t=1}^{N} \lambda_{t}\left\{\sum_{k=1}^{t} \sum_{j=1}^{J}\left(\gamma u_{j k}+\widetilde{R}\right)-x_{t+1}\right\}
$$

Changing the order of the second summation in (1.B.4) gives

$$
L=\sum_{t=1}^{N} \beta^{t} \sum_{j=1}^{J} f\left(u_{j t}, x_{t}\right)+\sum_{t=1}^{N}\left\{\sum_{k=t}^{N} \lambda_{t} \sum_{j=1}^{J}\left(\gamma u_{j t}+\widetilde{R}\right)-x_{t+1} \lambda_{t}\right\}
$$

From this, the first order conditions for a maximum are given by

$$
\begin{gathered}
\frac{\partial L}{\partial x_{s}}=\beta^{s} \sum_{j=1}^{J} \frac{\partial f\left(u_{j s}, x_{s}\right)}{\partial x_{s}}-\lambda_{s-1}=0 \\
\frac{\partial L}{\partial u_{l s}}=\beta^{s} \frac{\partial f\left(u_{l s}, x_{s}\right)}{\partial u_{l s}}+\gamma \sum_{k=s}^{N} \lambda_{k}=0
\end{gathered}
$$

As before, the adjoint variable $\lambda_{t}$ is the marginal present value shadow price of the state variable at time $t$. Defining the transformation $\lambda_{k}=\beta^{k} \mu_{k}$ where $\mu_{k}$ is the marginal current value shadow price at time $k$ allows us to restate conditions (1.B.6) and (1.B.7) in the current value form:

$$
\begin{aligned}
& \sum_{j=1}^{J} \frac{\partial f\left(u_{j s}, x_{s}\right)}{\partial x_{s}}-\beta^{-1} \mu_{s-1}=0 \\
& \frac{\partial f\left(u_{l s}, x_{s}\right)}{\partial u_{l s}}+\gamma \sum_{k=s}^{N} \beta^{k-s} \mu_{k}=0
\end{aligned}
$$

Noting that condition (1.B.9) implies that $\partial f\left(u_{i s}, x_{s}\right) / \partial u_{i s}=\partial f\left(u_{j s}, x_{s}\right) / \partial u_{j s}$ for all $i$ and $j$, we know that $u_{i s}=u_{j s}$. Because there is only one state variable, this means that condition (1.B.8) may be rewritten as

$$
J \frac{\partial f\left(u_{s}, x_{s}\right)}{\partial x_{s}}-\beta^{-1} \mu_{s-1}=0
$$


Conditions (1.B.9) and (1.B.10) are identical to the necessary conditions found in most simple renewable resource problems. Condition (1.B.9) states that the marginal benefit of an additional unit of pumping for each groundwater user should be set equal to the shadow price of an additional unit of water held in the aquifer, multiplied by the constant of proportionality $\gamma$. In condition (1.B.10), the shadow price of an additional unit of water is set equal to the aggregate marginal benefit of having one further unit of pumping lift. In this case, both of these terms will be negative.

By setting the number of time periods to infinity, the steady state condition may be obtained. At a steady state, condition (1.B.10) becomes

$$
\mu^{*}=\beta J \frac{\partial f\left(u^{*}, x^{*}\right)}{\partial x^{*}}
$$

Substituting this into the steady-state version of condition (1.B.9) gives

$$
\frac{\partial f\left(u^{*}, x^{*}\right)}{\partial u^{*}}+\gamma J \sum_{k=s}^{\infty} \beta^{k-s+1} \frac{\partial f\left(u^{*}, x^{*}\right)}{\partial x^{*}}=0
$$

This expression may be simplified by noting that in the steady state, $\partial f\left(u^{*}, x^{*}\right) / \partial x^{*}$ does not depend on time, so that the steady state condition may be simplified to

$$
\frac{\partial f\left(u^{*}, x^{*}\right)}{\partial u^{*}}=-\gamma J \frac{\partial f\left(u^{*}, x^{*}\right)}{\partial x^{*}} \sum_{k=1}^{\infty} \beta^{k}=\frac{-\gamma J}{\delta} \frac{\partial f\left(u^{*}, x^{*}\right)}{\partial x^{*}}
$$

where $\delta$ is the per-period interest rate. Equation (1.B.13), of course, is identical to the steady state condition obtained by using a difference equation as the equation of motion for the control variable.

\section{Appendix: Recovering optimality conditions for a single-cell aquifer from the general model}

Although necessary conditions (1.7) and (1.9) were derived in the context of the path-dependent, spatially heterogeneous groundwater application, they are also general conditions for optimality of a wider range of resource models. For example, they can be used to recover the first order conditions for the traditional discrete time single-cell aquifer problem (e.g [3]). This involves adding the two assumptions that define the single-cell model. First, the assumption that there is no spatial interdependency between distributed users allows the number of state variables to be reduced to one and condition (1.9) to be restated as

$$
\frac{\partial f\left(u_{l s}, x_{s}\right)}{\partial u_{l s}}+\sum_{t=s}^{N} \beta^{t-s} \widetilde{\theta}(t-s) \mu_{t}=0
$$

where the new weighting function $\widetilde{\theta}(t-s)$ no longer contains spatial arguments. As a result of the reduction in the number of state variables, in condition (1.C.1) 
the adjoint variable is analogous to the sum of all $J$ adjoint variables in condition (1.9). The additional assumption of path-independence of the resource stock allows the weighting function to be passed through the summation, giving

$$
\frac{\partial f\left(u_{l s}, x_{s}\right)}{\partial u_{l s}}+\gamma \sum_{t=s}^{N} \beta^{t-s} \mu_{t}=0
$$

The weighting function becomes a parameter, defined here as $\gamma$. It is a constant of proportionality that links a unit extraction of groundwater to the resultant change in the stock variable. Condition (1.C.2) exactly reproduces necessary condition (1.B.9) from Appendix B, where for reference, the single-cell resource extraction problem is solved in its entirety. With appropriate weighting functions, two-cell or multi-cell groundwater extraction problems can be recovered in a similar fashion.

\section{Notes}

1. The literature on the economics of groundwater extraction stretches back to the late 1950 s and early 1960s [18, 24]. Economic studies of groundwater extraction have followed several broad themes. Early contributions derived optimization rules for the management of groundwater resources [3, 4]. Critiques of this body of work originally focused on the magnitude of the welfares difference between optimal control rules and competitive outcomes $[11,12]$. In recent years, a further body of literature considering groundwater extraction as a differential game has emerged [20, 23].

2. Some 'two-cell' aquifer models actually contain more than two linked cells. The critical distinction between two-cell and true multi-cell models is that in two-cell models, all cells are directly connected with all others. Hence, any perturbation in one cell is immediately transmitted to all others.

3. We assume that both the number of resource users and their locations are exogenous. Incorporating endogenous well locations is beyond the scope of the current work, but for a genetic algorithm approach to a very simple well location problem, see Hsiao and Chang [13].

4. A few existing papers have presented continuous-time models with lagged effects that are analogous to the discrete time model presented here $[14,19]$. These results have been used to consider such issues as optimal advertising policy and the optimal durability of products.

5. Note that the transformation to current values means that the adjoint variable equals the difference between the current value shadow price in period $k$ and the discounted current value shadow price in period $k+1$. Hence, although $\mu_{j k}$ represents a difference in shadow prices between two successive periods, it is nonzero at a steady state.

6. Conversely, in the single-cell aquifer model, the only aggregate steady state pumping rate is that which exactly matches the per-period recharge.

\section{References}

[1] Allen, R.C., and Gisser, M., 1984, Competition versus optimal control in groundwater pumping when demand is nonlinear, Water Resources Research, v. 20, p. 752-756.

[2] Bredehoeft, J.D., and Young, R.A., 1970, The temporal allocation of groundwater - a simulation approach, Water Resources Research, v. 6, p. 3-21. 
[3] Brown, G., Jr., and Deacon, R., 1972, Economic optimization of a singlecell aquifer, Water Resources Research, v. 8, p. 557-564.

[4] Burt, O.R., 1964, The economics of conjunctive use of ground and surface water, Hilgardia, v. 32, p. 31-111.

[5] Burt, O.R., 1970, Groundwater storage control under institutional restrictions, Water Resources Research, v. 6, p. 1540-1548.

[6] Chakravorty, U., and Umetsu, C., 2003, Basinwide water management: a spatial model, Journal of Environmental Economics and Management, v. 45, p. 1-23.

[7] Domenico, P.A., 1972, Concepts and models in groundwater hydrology, McGraw-Hill, New York, 405 p.

[8] Eswaran, M., and Lewis, T., 1984, Appropriability and the extraction of a common property resource, Economica, v. 51, p. 393-400.

[9] Feinerman, E., 1988, Groundwater management: Efficiency and equity considerations, Agricultural Economics, v.2, p. 1-18.

[10] Freeze, R.A., and Cherry, J.A., 1979, Groundwater, Prentice-Hall, Englewood Cliffs, New Jersey, 604 p.

[11] Gisser, M., 1983, Groundwater: focusing on the real issue, Journal of Political Economy, v. 91, p. 1001-1027.

[12] Gisser, M., and Sanchez, D.A., 1980, Competition versus optimal control in groundwater pumping, Water Resources Research, v. 16, p. 638-642.

[13] Hsiao, C.-T., and Chang, L.-C., 2002, Dynamic optimal groundwater management with inclusion of fixed costs, Journal of Water Resources Planning and Management, v. 128, p. 57-65.

[14] Kamien, M.I., and Muller, E., 1976, Optimal control with integral state equations, Review of Economic Studies, v. 43, p. 469-473.

[15] Khalatbari, F., 1977, Market imperfections and the optimum rate of depletion of natural resources, Economica, v. 44, p. 409-414.

[16] Koundouri, P., 2004, Potential for groundwater management: GisserSanchez effect reconsidered, Water Resources Research, v. 40, WO6S16, doi:10.1029/2003WR002164.

[17] Libecap, G.D., and Wiggins, S.N., 1985, The influence of private contractual failure on regulation: the case of oil field unitization, Journal of Political Economy, v. 93, p. 690-714.

[18] Milliman, J.W., 1956, Commonality, the price system, and use of water supplies, Southern Economic Journal, v. 22, p. 426-437.

[19] Muller, E., and Peles, Y.C., 1990, Optimal dynamic durability, Journal of Economic Dynamics and Control, v. 14, p. 709-719. 
[20] Negri, D.H., 1989, The common property aquifer as a differential game, Water Resources Research, v. 25, p. 9-15.

[21] Noel, J.E., Gardner, B.D., and Moore, C.V., 1980, Optimal regional conjunctive water management, American Journal of Agricultural Economics, v. 62 , p. $489-498$.

[22] Noel, J.E., and Howitt, R.E., 1982, Conjunctive multibasin management: an optimal control approach, Water Resources Research, v. 18, p. 753-763.

[23] Provencher, B., and Burt, O., 1993, The externalities associated with the common property exploitation of groundwater, Journal of Environmental Economics and Management, v. 24, p. 139-158.

[24] Renshaw, E.F., 1963, The management of ground water reservoirs, Journal of Farm Economics, v. 45, p. 285-295.

[25] Theis, C.V., 1935, The relation between the lowering of the piezometric surface and the rate and duration of discharge of a well using groundwater storage, Transactions American Geophysical Union, v. 2, p. 519-524.

[26] Wiggins, S.N., and Libecap, G.D., 1984, Oil field unitization: contractual failure in the presence of imperfect information, American Economic Review, v. 75, p. 368-385.

[27] Zeitouni, N., and Dinar, A., 1997, Mitigating negative water quality and quality externalities by joint management of adjacent aquifers, Environmental and Resource Economics, v. 9, p. 1-20. 